\title{
Qualidade nutricional da alimentação em escolas de Realeza-PR
}

\author{
Nutritional quality of school meals in schools of Realeza City (Brazil)
}

\section{Calidad nutricional de la alimentación en escuelas de la ciudad de Realeza (Brasil)}

RESUMo O objetivo foi avaliar o cumprimento das recomendações nutricionais da Resolução $n^{\circ}$. 26/2013, na oferta e consumo da alimentação escolar, em duas escolas municipais de Realeza-PR. Analisaram-se dez preparações por escola e o consumo de frutas/hortaliças de uma semana. A alimentação escolar ofertada de 6-10 anos de idade foi adequada para energia, carboidratos e lipídeos, excessiva para proteína e insuficiente para micronutrientes. O consumo de energia e macronutrientes atendeu às recomendações, mas foi insuficiente para micronutrientes. A oferta para alunos de 11-15 anos de idade foi apropriada para energia, macronutrientes e ferro, mas o consumo teve adequação somente para proteínas; os micronutrientes não foram suficientes. $\mathrm{O}$ consumo de frutas e hortaliças foi adequado. A oferta da alimentação escolar supriu as recomendações dos macronutrientes para as duas faixas etárias, porém a oferta dos micronutrientes teve menor adequação. $\mathrm{O}$ consumo não atingiu a mesma recomendação quando comparado à oferta, indicando problemas com a aceitabilidade da alimentação, especialmente entre 11-15 anos de idade.

Palavras-chave: Saúde Escolar. Nutrientes. Políticas Públicas de SAúde.

Aвstract We seek to evaluate the compliance with the nutritional recommendations set out in Ordinance $n^{\circ}$. 26/2013, regarding to the offer and the consumption of feeding scholar, in two elementary schools of Realeza city (South of Brazil). Ten recipes from each school, and the weekly consumption of fruit/vegetables were evaluated. The school meals offered to 6-10-years-old students were adequate in energy, carbohydrates, lipids, and iron, but above the normal to protein, and insufficient for micronutrients. The food intake was adequate in energy and macronutrients, while the micronutrients did not reach the recommendation. The food offering for 11-15-years-old students was adequate in energy, macronutrients and iron, while the consumption was adequate only for proteins; offering and consumption of micronutrients showed no nutritional adequacy. The consumption of fruit/vegetables was adequate. At the end, it was observed an adequate offering of macronutrients 
Moreover, the food intake in the schools was lower than de offering, what can indicate a low acceptability, especially among 11-15-years-old students. Key-words: School Health. Nutritients. National Health PoliCIES.

\section{RESUMEN}

El objetivo fue evaluar el cumplimiento de las recomendaciones nutricionales de la Resolución nº. 26/2013, en la oferta y consumo de la alimentación escolar, en dos escuelas municipales de Realeza-PR. Se analizaron diez preparaciones por escuela y el consumo de frutas / hortalizas de una semana. La alimentación escolar ofrecida de 6-10 años de edad fue adecuada para energía, carbohidratos y lípidos, excesiva para proteína e insuficiente para micronutrientes. El consumo de energía y macronutrientes atendió a las recomendaciones, pero fue insuficiente para los micronutrientes. La oferta para alumnos de 11-15 años de edad fue apropiada para energía, macronutrientes y hierro, pero el consumo tuvo adecuación sólo para proteínas; Los micronutrientes no fueron suficientes. El consumo de frutas y hortalizas fue adecuado. La oferta de la alimentación escolar suplió las recomendaciones de los macronutrientes para las dos edades, pero la oferta de los micronutrientes tuvo menor adecuación. El consumo no alcanzó la misma recomendación en comparación con la oferta, indicando problemas con la aceptabilidad de la alimentación, especialmente entre 11-15 años de edad.

Palabras clave: Salud Escolar. Nutrientes. Políticas Públicas de SALUd.

\section{INTRODUÇÃO}

A alimentação adequada e saudável é um direito fundamental do ser humano, com reconhecimento internacional e ratificação brasileira por meio do Pacto Internacional de Direitos Econômicos, Sociais e Culturais (PIDESC). ${ }^{1}$ Também é considerada essencial e indispensável, direito previsto na Constituição Federal do Brasil, em que o poder público deve promover planos e ações políticas necessárias para promover e garantir a segurança alimentar e nutricional da população. $^{2}$

Nesse contexto, a alimentação escolar é um programa inteiramente pautado pelo Direito Humano à Alimentação Adequada (DHAA), que visa garantir a segurança alimentar e nutricional dos alunos, ofertando acesso universal e igualitário, e respeitando as diferenças biológicas entre idades e condições de saúde dos alunos que necessitem de atenção específica e que se encontrem em vulnerabilidade social. ${ }^{3,4}$

Quanto às necessidades nutricionais diárias da alimentação escolar, observa-se na legislação vigente que as refeições oferecidas devem suprir no mínimo $20 \%$ das necessidades nutricionais diárias quando ofertada uma refeição, para os alunos matriculados na educação básica de ensino fundamental, em período parcial, que não sejam de comunidades indígenas e remanescentes de quilombos. ${ }^{4,5}$ A importância do consumo de frutas e hortaliças igualmente é ressaltada na legislação do PNAE, que estabelece a oferta desses alimentos a um mínimo de 200 gramas semanais por aluno. ${ }^{5}$

Poucos estudos atuais, no Brasil, debruçaram-se em avaliar a adequação do 
fornecimento nutricional das refeições escolares, sendo o foco dos estudos recentes a análise qualitativa dos cardápios, ${ }^{6,7}$ da gestão administrativa do programa, ${ }^{8}$ a compra da agricultura familiar, ${ }^{910} \mathrm{e}$ a inserção de orgânicos na alimentação escolar. ${ }^{11}$ Portanto, este estudo teve por objetivo avaliar a qualidade nutricional das refeições servidas e consumidas durante três meses na alimentação escolar do município de Realeza-PR, visando observar se as necessidades nutricionais diárias estão sendo supridas conforme preza a Resolução $\mathrm{n}^{\circ}$. 26, de 17 de junho de 2013/MEC/FNDE, em duas diferentes faixas etárias. ${ }^{5}$

\section{Métodos}

\section{Local e sujeitos}

O estudo foi realizado em duas escolas da rede municipal de ensino fundamental, sendo ambas localizadas na zona urbana do município de Realeza-PR. Essas escolas foram escolhidas porque atendem em período parcial e fornecem uma refeição para os alunos matriculados. A intenção das pesquisadoras era avaliar a refeição ofertada a todos aqueles que aderissem à refeição em cada dia avaliado e, assim, realizou-se censo da oferta e do consumo de nutrientes em ambas as escolas, ou seja, todos os alunos presentes em cada dia de avaliação e que aderiram às refeições servidas tiveram seu per capita contabilizado. Na Escola 1, a refeição que obteve maior adesão foi "sagu com suco de uva e maçã Fuji" e "biscoito integral com suco de soja sabor morango", consumida por 68 alunos. Já na Escola 2, a refeição de maior adesão foi procurada por 104 escolares, que se serviram de "cuca simples com iogurte sabor salada de frutas" e banana.

\section{Instrumentos e técnicas de coleta de dados}

Foram avaliadas dez refeições da alimentação escolar em cada escola, totalizando vinte preparações, sendo escolhidas as preparações/refeições do cardápio mensal através de sorteio. O cardápio era o mesmo para as duas escolas, sendo que é elaborado semestralmente pelo nutricionista responsável técnico, e se repete durante uma vez em cada semestre do ano letivo.

A coleta de dados realizou-se durante nove semanas, compreendendo os meses de julho a setembro de 2014. No Quadro 1 (na página seguinte) é possível verificar as 20 preparações que foram avaliadas no período.

Para verificar se havia especificidade quanto ao porcionamento da alimentação escolar por faixa etária, foi perguntado para as cozinheiras se as porções oferecidas possuíam diferenciação por idade.

Para a determinação da oferta alimentar, foi adotado o método de pesagem direta dos alimentos em gramas. Foi pesada uma porção da refeição após as preparações estarem prontas, na medida em que a cozinheira porcionava para os alunos. Todos os alimentos e preparações foram pesados com o auxílio de uma balança digital marca Ohaus corporation, com capacidade para 5.000 gramas e precisão de 1 grama. A quantidade da oferta da alimentação foi anotada em ficha onde havia especificado o alimento ou preparação, o peso do mesmo em gramas e a diferenciação por idade do aluno. Para os alunos que repetiram a refeição, foi realizada uma fila, na qual foi feita a anotação do número de alunos que repetiram a refeição. Essa medida foi importante porque contabilizou a oferta de mais alimentos, o que, por conseguinte, contribuiu para calcular a oferta real de nutrientes. 
Quadro 1 - Refeições avaliadas no período de julho, agosto e setembro de 2014 - Realeza-PR.

\begin{tabular}{|c|c|c|}
\hline Data & Escola & Cardápio \\
\hline $30 / 07$ & 1 & Arroz carreteiro, alface e banana caturra \\
\hline $31 / 07$ & 2 & Iogurte sabor salada de frutas, cuca simples e banana caturra \\
\hline $04 / 08$ & 1 & $\begin{array}{l}\text { Macarrão com carne moída, repolho branco, maçã Fuji e suco de soja sabor } \\
\text { morango }\end{array}$ \\
\hline $05 / 08$ & 1 & Sagu de suco de uva, biscoito integral, maçã Fuji e suco de soja sabor morango \\
\hline $08 / 08$ & 2 & Macarrão com salsicha e batata palha \\
\hline $11 / 08$ & 2 & Arroz carreteiro e repolho \\
\hline $13 / 08$ & 2 & Arroz branco, mandioca cozida e carne suína frita \\
\hline $18 / 08$ & 1 & Arroz carreteiro, repolho, maçã Fuji e suco de soja sabor morango \\
\hline $21 / 08$ & 1 & Iogurte sabor morango, cuca simples e maçã Fuji \\
\hline $22 / 08$ & 2 & Arroz branco e carne moída ao molho de tomate com batata inglesa \\
\hline $25 / 08$ & 2 & Macarrão com carne moída \\
\hline $26 / 08$ & 1 & Sagu de suco de uva, biscoito integral e maçã Fuji \\
\hline $29 / 08$ & 1 & Sopa de feijão com macarrão, biscoito integral e suco de soja sabor morango \\
\hline 02/09 & 2 & $\begin{array}{l}\text { Leite integral, composto lácteo com flocos sabor morango e cuca simples e maçã } \\
\text { Fuji }\end{array}$ \\
\hline $04 / 09$ & 1 & Chá Mate, cuca caseira e suco de soja suco de soja sabor morango \\
\hline $10 / 09$ & 2 & Arroz branco, feijão roxo, acelga e carne suína assada \\
\hline $11 / 09$ & 1 & Pão caseiro, doce de leite em pasta, suco natural de limão e maçã Fuji \\
\hline $12 / 09$ & 2 & Cookies integrais, banana e suco de soja sabor morango \\
\hline $15 / 09$ & 1 & Risoto de frango \\
\hline $19 / 09$ & 2 & Sopa de macarrão com frango, cenoura e brócolis e maçã Fuji \\
\hline
\end{tabular}

Para verificar o consumo alimentar após cada refeição, realizou-se a pesagem das sobras sujas da alimentação, que foram separadas por faixa etária, descartadas em duas lixeiras devidamente identificadas. Os valores obtidos por meio da pesagem das sobras sujas foram descontados do valor total servido aos escolares. As sobras lim- pas não foram pesadas porque a oferta da alimentação ultrapassava o público-alvo da pesquisa (alunos com menos de 6 anos ou mais de 15 anos de idade e professores), ficando inviável utilizar o método de pesagem das sobras limpas. Além disso, quantificar o que foi rejeitado é o suficiente para observar o quanto foi consumido, uma vez 
que os pratos foram pesados individualmente.

\section{Tratamento e análise dos dados}

A partir da pesagem dos alimentos e preparações, a composição centesimal (conteúdo de energia, fibras e nutrientes) foi pesquisada no software de avaliação e nutrição AVANUTRI, usando como filtros a Tabela Brasileira de Composição de Alimentos TACO, ${ }^{12}$ a Pesquisa de Orçamentos Familiares do Instituto Brasileiro de Geografia e Estatística, ${ }^{13}$ a Tabela de Composição de Alimentos de Philippi, ${ }^{14}$ e a informação do fabricante de rótulos coletados nas escolas. Os nutrientes pesquisados foram proteína, carboidrato, lipídeo, Vitamina A, ferro e cálcio. Vale ressaltar que as três tabelas de composição de alimentos utilizadas tinham as informações de todos os nutrientes pesquisados, incluindo os micronutrientes. Isso minimizou as possíveis diferenças existentes entre elas quanto à composição centesimal dos alimentos, uma vez que o software mescla dados de várias tabelas.

Após a obtenção dos valores dos macronutrientes e micronutrientes, foi realizada a comparação com os parâmetros estipulados pela Resolução no. 26/CD/FNDE, a fim de verificar se a alimentação fornecida e ingerida pelos alunos está atendendo ao Programa Nacional Alimentação Escolar recomendada. ${ }^{5}$ De acordo com o que estabelece a resolução, no que se refere ao fornecimento de uma refeição por dia, é necessário o suprimento de $20 \%$ das necessidades nutricionais diárias de energia para alunos do ensino fundamental. Na faixa etária de 6 a 10 anos, deve ser fornecido através da alimentação escolar 300 quilocalorias, 48,8 gramas de carboidratos, 9,4 gramas de proteínas, 7,5 gramas de lipídeos, 5,4 gramas de fibras, 210 miligramas de cálcio e 1,8 miligramas de ferro. ${ }^{5}$ Para alunos de 11 a 15 anos de idade, deve ser ofertada uma refeição que supra $20 \%$ das necessidades nutricionais diárias, contendo 435 quilocalorias, 70,7 gramas de carboidratos, 13,6 gramas de proteínas, 10,9 gramas de lipídios, 6,1 gramas de fibras, 260 miligramas de cálcio e 2,1 miligramas de ferro. ${ }^{5}$

Quanto à avaliação do consumo de frutas e hortaliças, foi escolhida aleatoriamente uma semana do cardápio mensal, diferente daquelas em que as demais 20 preparações foram avaliadas. Nessa semana, foi realizada a pesagem da oferta desses alimentos todos os dias letivos, em ambas as escolas. A avaliação do consumo de frutas e hortaliças foi feita com os alunos de 6 a 15 anos de idade.

Em relação às sobras sujas das frutas e hortaliças, as mesmas foram separadas em dois lixeiros, em que o primeiro era designado para alunos de 4 e 5 anos de idade e professores, e o segundo para alunos de 6 a 15 anos, em que foi descontado a quantidade em gramas das sobras das frutas e hortaliças. Assim, foi possível obter o valor mais aproximado da realidade quanto ao consumo de frutas e hortaliças. As sobras sujas de alunos de 4 e de 5 anos de idade e professores foram excluídas posteriormente, pois o PNAE não estabelece a oferta de frutas e hortaliças para essa faixa etária, somente para alunos de 6 a 15 anos de idade. ${ }^{5}$ A partir da quantidade em gramas da ingestão das frutas e hortaliças por aluno durante a semana, foi verificado se a quantidade consumida per capita desses alimentos atende ao estipulado pela Resolução $n^{\circ}$. 26/MEC/FNDE, o qual recomenda 
que os cardápios devem oferecer, no mínimo, três porções de frutas e hortaliças por semana (200g/aluno/semana). ${ }^{5}$

\section{Análises estatísticas}

Os valores dos nutrientes referentes à oferta e consumo da alimentação escolar foram apresentados por medidas de tendência central (médias e respectivos desvios-padrão) e, com base na legislação, foi observado o percentual de atendimento da necessidade nutricional de cada nutriente avaliado, por faixas etárias. Foram considerados adequados os nutrientes que atingiram o patamar de referência entre $80-120 \%$ das recomendações do PNAE, margem utilizada também por Matihara et al. ${ }^{15}$ na sua pesquisa sobre valor nutricional e aceitabilidade da alimentação escolar.

\section{Aspectos Éticos da pesquisa}

A pesquisa foi realizada com o consentimento da secretaria da educação do município.

\section{RESULTADOS E DISCUSSÃo}

Verificou-se que o cardápio das escolas não foi seguido, pois entre as 20 avaliações realizadas na pesquisa somente uma foi executada conforme a listagem exata dos alimentos e preparações do cardápio. Em oito ocasiões os alimentos foram trocados por similares. Quanto aos demais dias, não foram seguidos conforme o cardápio proposto, fato esse que também foi verificado em pesquisa realizada por Neitzke et al. ${ }^{16}$ sobre adequação nutricional da alimentação escolar.

A Tabela 1 indica a média aritmética geral da oferta e consumo de nutrientes e energia da alimentação ofertada nos 20 dias avaliados para alunos de 6 a 10 anos de idade, bem como, a adequação da oferta e do consumo da alimentação quanto aos parâmetros do PNAE.

Tabela 1 - Recomendação, média aritmética geral, desvio-padrão e adequação da oferta e do consumo no PNAE, na faixa etária de 6 a 10 anos - Realeza-PR, 2014.

\begin{tabular}{|c|c|c|c|c|c|c|c|}
\hline \multirow[b]{2}{*}{ Nutriente } & \multirow{2}{*}{$\begin{array}{l}\text { Recom. } \\
\text { PNAE }\end{array}$} & \multicolumn{3}{|c|}{ Oferta da alimentação } & \multicolumn{3}{|c|}{ Consumo da alimentação } \\
\hline & & MAG & DP & $\operatorname{ADQ}(\%)$ & MAG & DP & ADQ (\%) \\
\hline Energia (Kcal) & 300 & 335,79 & 120,78 & 111,93 & 281,16 & 116,85 & 93,72 \\
\hline $\mathrm{CHO}(\mathrm{g})$ & 48,8 & 51,71 & 33,80 & 105,96 & 44,69 & 32,65 & 91,58 \\
\hline PTN (g) & 9,4 & 12,57 & 7,67 & 133,72 & 9,89 & 5,49 & 105,21 \\
\hline $\operatorname{LIP}(\mathrm{g})$ & 7,5 & 8,74 & 6,14 & 116,53 & 6,99 & 4,52 & 93,2 \\
\hline Fibras (g) & 5,4 & 2,74 & 3,02 & 50,74 & 2,12 & 2,07 & 39,26 \\
\hline Vit. A (mcg) & 100 & 24,56 & 37,29 & 24,56 & 18,97 & 26,36 & 18,97 \\
\hline Cálcio (mg) & 210 & 47,54 & 48,77 & 22,64 & 36,30 & 39,35 & 17,29 \\
\hline Ferro (mg) & 1,8 & 1,74 & 1,38 & 96,67 & 1,24 & 0,75 & 68,89 \\
\hline
\end{tabular}

Recom: Recomendação; MAG: Média aritmética geral; DP: Desvio-padrão; ADQ: Adequação; Kcal: Quilocalorias; CHO: Carboidratos; PTN: Proteínas; LIP: Lipídeos; Vit. A: Vitamina A; g: gramas; mg: miligramas; mcg: microgramas. 
No que se refere à oferta de energia, encontra-se de acordo com a recomendação, com 111,9\% de adequação, resultado que concorda com pesquisa realizada em $\mathrm{Ma}$ ringá-PR, com escolares do $1^{\circ}$. ao $5^{\circ}$. ano. ${ }^{17}$ Matihara et al., para alunos de 8 a 11 anos de idade, também observaram que a oferta de energia no PNAE encontrava-se dentro da recomendação. ${ }^{15}$

Verificou-se adequação da oferta de carboidratos com percentual de 105,9\%, para alunos na faixa etária de 6 a 10 anos. Alves et al. em Maringá (PR), ao contrário, observaram oferta de carboidratos abaixo do recomendado, com o conteúdo de lipídeos garantindo a oferta de energia. ${ }^{17}$

Quanto à oferta de lipídeos em Realeza, o percentual encontrava-se de acordo com a margem de recomendação, com 116,6\% de adequação. Silva e Gregório avaliaram a oferta da alimentação escolar para alunos de 6 a 10 anos e de 11 a 15 anos de idade, em que foram avaliados 20 dias de cardápio. Vale destacar que o método para estimar a oferta de alimentos foi diferente neste estudo. Os autores separaram o cardápio pelos seus ingredientes e, a partir da composição dos ingredientes e do per capita cedido pela secretaria municipal de educação, observaram elevada oferta de lipídeos tanto para os alunos de 6 a 10 anos como os de 11 a 15 anos. ${ }^{18} \mathrm{O}$ mesmo ocorreu em Maringá-PR, no qual a oferta de lipídeos excedeu à recomendação. ${ }^{17}$

A oferta de proteína no nosso estudo, por sua vez, está acima do recomendado, com adequação de $133,7 \%$, resultado que coincide com a pesquisa de Matihara et al., que avaliaram a oferta de 14 refeições de crianças de 8 a 11 anos de idade. ${ }^{15}$

Ao verificar o consumo de energia e macronutrientes, para a mesma faixa etária, ob- serva-se que o consumo de energia $(93,72 \%)$, carboidratos $(91,58 \%)$, proteínas $(105,21 \%)$ e lipídeos $(93,2 \%)$ atingiram a recomendação. Dessa forma, apesar da oferta de proteínas ter sido alta, o consumo esteve dentro do adequado provavelmente por conta das sobras, o que indica a necessidade de melhorias no planejamento da oferta de carnes.

Já as fibras, vitamina A e cálcio não foram ofertados em quantidade recomendada para a idade dos alunos e, por conseguinte, o consumo desses nutrientes não atendeu aos parâmetros do PNAE. Em pesquisa realizada por Azevedo et al., a vitamina A foi ofertada em excesso $(277,9 \%)$, o cálcio não atingiu um terço do valor recomendado $(29,4 \%)$ e a oferta de ferro também ficou abaixo do esperado (63,2\%), de 6 a 10 anos de idade. ${ }^{19}$ Em pesquisa que avaliou a oferta da alimentação escolar para alunos de 6 a 10 anos de idade em um município rural do Espírito Santo, a oferta de cálcio apresentou adequação de 55,4\%, encontrando-se também abaixo da recomendação do PNAE, mas a oferta de Vitamina A ficou acima do recomendado (202,1\% de adequação). ${ }^{16}$ Durante a fase de crescimento, o suprimento adequado de cálcio é essencial no desenvolvimento ósseo, por isso a dieta deve ter quantidade suficiente desse nutriente. ${ }^{17}$ Quanto à oferta de vitamina $\mathrm{A}$, também não atingiu os parâmetros do PNAE em uma escola de Maringá-PR, com escolares de $1^{\text {a }}$. a $4^{\text {a }}$. série do ensino fundamental. ${ }^{20}$

A Tabela 2 indica a média aritmética geral da oferta e consumo da alimentação para alunos de 11 a 15 anos de idade nas duas escolas, o desvio padrão por nutriente da oferta e do consumo da alimentação escolar e a adequação da oferta e do consumo da alimentação quanto aos parâmetros do PNAE. 
Tabela 2 - Recomendação, média aritmética geral, desvio-padrão e adequação da oferta e consumo das refeições oferecidas pelo PNAE na faixa etária de 11 a 15 anos - Realeza-PR, 2014.

\begin{tabular}{llllllll}
\hline Nutriente & \multirow{2}{*}{$\begin{array}{l}\text { Recom. } \\
\text { PNAE }\end{array}$} & \multicolumn{2}{c}{ Oferta da alimentação } & \multicolumn{3}{c}{ Consumo da alimentação } \\
\cline { 3 - 8 } & & MAG & DP & ADQ (\%) & MAG & DP & ADQ (\%) \\
\hline Energia (Kcal) & 435 & 393,51 & 182,71 & 90,46 & 341,19 & 209,40 & 78,43 \\
CHO (g) & 70,7 & 60,79 & 50,28 & 85,98 & 54,58 & 53,03 & 77,20 \\
PTN (g) & 13,6 & 15,03 & 8,65 & 110,51 & 12,13 & 8,18 & 89,19 \\
LIP (g) & 10,9 & 10,03 & 6,90 & 92,02 & 8,26 & 6,41 & 75,78 \\
Fibras (g) & 6,1 & 3,03 & 3,23 & 49,67 & 2,42 & 2,78 & 39,67 \\
Vit. A (mcg) & 140 & 28,31 & 39,06 & 20,22 & 24,97 & 33,92 & 17,84 \\
Cálcio (mg) & 260 & 54,73 & 49,15 & 21,05 & 42,41 & 42,99 & 16,31 \\
Ferro (mg) & 2,1 & 1,99 & 1,50 & 94,76 & 1,46 & 1,14 & 69,52 \\
\hline
\end{tabular}

Recom: Recomendação; MAG: Média aritmética geral; DP: Desvio-padrão; ADQ: Adequação; Kcal: Quilocalorias; CHO: Carboidratos; PTN: Proteínas, LIP: Lipídeos; Vit. A: Vitamina A; G: gramas; mg: miligramas; mcg: microgramas.

Quanto à oferta da alimentação escolar para alunos de 11 a 15 anos de idade, verificou-se que a energia e, por conseguinte, os macronutrientes atenderam ao que o PNAE estabelece. ${ }^{5}$ No entanto, o consumo foi insuficiente para energia $(78,4 \%)$, carboidratos $(77,2 \%)$ e lipídeos $(75,8 \%)$, apresentando-se dentro do esperado apenas para proteínas, o que indica fortemente uma baixa aceitabilidade das refeições ou, ainda, um porcionamento insuficiente de alimentos para os adolescentes. No que se refere aos micronutrientes, somente a oferta do ferro atingiu a adequação (94,8\%).

Ao se analisarem ambas as faixas etárias, observa-se que houve maior adequação da alimentação escolar quanto à oferta e consumo para alunos de 6 a 10 anos de idade. Esse resultado pode se dever ao fato de que em uma das escolas da pesquisa a cozinheira relatou que não faz diferenciação das porções por idade, ou seja, todos os alunos independentemente da idade recebem a mesma quantidade de alimento. Neitzke et al. também observaram que não havia padronização nas porções dos alimentos ofertadas aos alunos. ${ }^{16}$ A Resolução n ${ }^{\circ}$. 26/MEC/FNDE/2013 ressalta a necessidade da diferenciação das porções, para a garantia das necessidades nutricionais dos alunos de acordo com a faixa etária em que se encontram. ${ }^{5}$

A aceitabilidade da alimentação escolar é outro fator que pode ter influenciado no percentual de adequação menor para os alunos de 11 a 15 anos de idade. Pesquisa que verificou a aceitabilidade da alimentação escolar no mesmo município dessa pesquisa, com escolares do $1^{\circ}$. ao $5^{\circ}$. ano que frequentavam a escola em período integral, averiguou que a aceitabilidade da alimentação escolar encontrou-se em 85,9\%, sendo considerada adequada conforme a escala hedônica, porém no limite, pois o PNAE estabelece que o índice de aceitabilidade deve apresentar-se acima de $85 \% .^{21}$

Com o intuito de observar a oferta e o consumo nas duas escolas de forma independente, vê-se na Tabela 3 o percentual de adequação de cada uma das escolas, por faixas etárias. 
Tabela 3 - Percentual de adequação da oferta e do consumo da alimentação escolar, por faixas etárias - Realeza-PR, 2014.

\begin{tabular}{|c|c|c|c|c|}
\hline \multirow[b]{3}{*}{ Nutrientes } & \multicolumn{4}{|c|}{6 a 10 anos de idade } \\
\hline & \multicolumn{2}{|c|}{ Adequação oferta (\%) } & \multicolumn{2}{|c|}{ Adequação consumo (\%) } \\
\hline & Escola 1 & Escola 2 & Escola 1 & Escola 2 \\
\hline Energia (Kcal) & 118,07 & 105,80 & 104,5 & 82,94 \\
\hline Carboidratos (gramas) & 129,67 & 82,27 & 115,76 & 67,38 \\
\hline Proteínas (gramas) & 103,40 & 164,04 & 89,36 & 120,96 \\
\hline Lipídeos (gramas) & 92,13 & 140,93 & 79,87 & 106,4 \\
\hline Fibras (gramas) & 35,74 & 65,74 & 30,56 & 47,78 \\
\hline Vitamina A $(\mathrm{mcg})^{*}$ & 12,11 & 37 & 10,6 & 27,34 \\
\hline Cálcio (miligramas) & 17,10 & 28,07 & 15,42 & 19,14 \\
\hline \multirow[t]{3}{*}{ Ferro (miligramas) } & 77,22 & 116,11 & 66,67 & 70,56 \\
\hline & \multicolumn{4}{|c|}{11 a 14 anos de idade } \\
\hline & \multicolumn{2}{|c|}{ Adequação oferta (\%) } & \multicolumn{2}{|c|}{ Adequação consumo (\%) } \\
\hline Nutrientes & Escola 1 & Escola 2 & Escola 1 & Escola 2 \\
\hline Energia (Kcal) & 112,34 & 72,96 & 103,03 & 58,75 \\
\hline Carboidratos (gramas) & 122,50 & 56,78 & 116,14 & 46,04 \\
\hline Proteínas (gramas) & 106,84 & 113,38 & 89,56 & 88,90 \\
\hline Lipídeos (gramas) & 85,78 & 96,97 & 72,38 & 78,53 \\
\hline Fibras (gramas) & 39,18 & 58,20 & 31,80 & 46,07 \\
\hline Vitamina A $(\mathrm{mcg})^{*}$ & 12,46 & 26,43 & 11,67 & 22,76 \\
\hline Cálcio (miligramas) & 19,02 & 22,67 & 17,06 & 15,71 \\
\hline Ferro (miligramas) & 88,57 & 99,52 & 75,71 & 64,76 \\
\hline
\end{tabular}

*mcg: microgramas

No que diz respeito à oferta da alimentação na Escola 1, observa-se adequação da oferta de energia, proteínas e lipídeos, na faixa etária de 6 a 10 anos. Já a Escola 2 teve adequação na oferta de energia, carboidratos e ferro, e excesso de oferta de proteínas e lipídeos. No que se refere ao consumo, a Escola 1 possuiu maior adequação (energia, carboidratos e proteínas), enquanto a Escola 2 apresentou consumo de proteínas acima do recomendado.

Quanto ao percentual de adequação para alunos de 11 a 15 anos de idade, a ofer- ta da alimentação escolar na Escola 1 obteve maior adequação, com quilocalorias atingindo $112,3 \%$, proteínas $106,8 \%$, lipídeos $85,8 \%$ e ferro $88,6 \%$. A oferta dos carboidratos ultrapassou a margem estabelecida, com adequação de $122,5 \%$.

O consumo da alimentação escolar apresenta maior adequação na Escola 1, onde os nutrientes com adequação são as quilocalorias $103,0 \%$, carboidratos $116,14 \%$, proteínas $89,56 \%$, enquanto na Escola 2 somente as proteínas apresentam adequação, com $88,9 \%$. 
Observa-se que a proteína foi o único nutriente que apresenta adequação para oferta e consumo nas duas escolas para a faixa etária de 11 a 15 anos.

Os resultados indicam que a Escola 1 foi a que apresentou maior adequação comparando com a Escola 2 para as duas faixas etárias da pesquisa.

Observa-se que na Escola 2 a oferta de proteína ultrapassou a recomendação tanto para a oferta quanto para o consumo para os alunos de 6 a 10 anos de idade. Ao observar as refeições sorteadas, verifica-se que houve maior número de refeições com carne na Escola 2, o que pode ter influenciado esse resultado.
A partir dos resultados, é possível verificar que a oferta e o consumo da alimentação escolar para ambas as faixas etárias indicaram variação onde a oferta encontrou maior adequação aos parâmetros do PNAE, fator esse que deve ser observado, pois a alimentação está em alguns casos sendo ofertada em quantidade suficiente, porém os alunos não estão ingerindo toda a quantidade ofertada.

A Tabela 4 indica o consumo de frutas e hortaliças das duas escolas da pesquisa, onde a faixa etária verificada foi de 6 a 15 anos, sendo excluídos os alunos que não se enquadravam na faixa etária indicada.

Tabela 4 - Consumo semanal de frutas e hortaliças, média aritmética e adequação de alunos de 6 a 15 anos de idade - Escola 1 e 2 - Realeza-PR, 2014.

\begin{tabular}{|c|c|c|c|c|c|c|}
\hline Dia & Escola & Frutas e hortaliças & $\begin{array}{c}{ }^{*} \text { Total ofertado } \\
\text { (gramas) }\end{array}$ & $\begin{array}{l}\text { No. Alunos } \\
\text { (6-15 anos de } \\
\text { idade) }\end{array}$ & $\begin{array}{c}\text { Sobra } \\
\text { (gramas) } \\
6-15 \text { anos } \\
\text { de idade }\end{array}$ & $\begin{array}{c}\text { Per capita } \\
\text { consumido } \\
(6-15 \text { anos de } \\
\text { idade) (gramas) }\end{array}$ \\
\hline 1 & 1 & Maçã Fuji & 2931 & 77 & \multirow{2}{*}{177} & 27,97 \\
\hline 1 & 1 & Alface & 180 & 77 & & 1,71 \\
\hline 1 & 2 & Beterraba & 8641 & 47 & \multirow{2}{*}{754} & 139,94 \\
\hline 1 & 2 & Cenoura & 230 & 47 & & 3,72 \\
\hline 2 & 1 & Banana Caturra & 11678 & 78 & 3917 & 73,09 \\
\hline 2 & 2 & Maçã Fuji & 12943 & 65 & 1507 & 158,84 \\
\hline 3 & 1 & Maçã Fuji & 2738 & 68 & \multirow{2}{*}{95} & 30,06 \\
\hline 3 & 1 & Repolho & 1390 & 68 & & 15,26 \\
\hline 3 & 2 & $\begin{array}{l}\text { Repolho com } \\
\text { Tomate }\end{array}$ & 3856 & 62 & 748 & 45,04 \\
\hline 4 & 1 & Maçã Fuji & 2639 & 78 & 78 & 27,62 \\
\hline 4 & 2 & Banana & 18767 & 164 & 3142 & 74,30 \\
\hline 5 & 1 & Maçã & 2166 & 61 & \multirow[b]{2}{*}{90} & 29,75 \\
\hline 5 & 1 & Cenoura & 400 & 61 & & 5,60 \\
\hline \multicolumn{5}{|c|}{ Consumo de frutas e hortaliças Escola 1 (gramas) } & \multicolumn{2}{|r|}{211,06} \\
\hline \multicolumn{5}{|c|}{ Consumo de frutas e hortaliças Escola 2 (gramas) } & \multicolumn{2}{|r|}{421,84} \\
\hline \multicolumn{5}{|c|}{ Média aritmética geral do consumo de frutas e hortaliças (gramas) } & \multicolumn{2}{|r|}{316,45} \\
\hline \multicolumn{5}{|c|}{ Adequação do consumo de frutas e hortaliças Escola 1 (\%) } & \multicolumn{2}{|r|}{105,53} \\
\hline \multicolumn{5}{|c|}{ Adequação do consumo de frutas e hortaliças Escola 2 (\%) } & \multicolumn{2}{|r|}{210,92} \\
\hline
\end{tabular}


Quanto ao consumo das frutas e hortaliças, verificou-se que o consumo atende ao estipulado pelo PNAE, ${ }^{5}$ pois a média aritmética apresentou-se com 316,5 gramas per capita durante a semana.

A Escola 2 teve maior consumo de frutas e hortaliças, com adequação de 210,9\% quanto à recomendação do PNAE. A Escola 1 também atendeu aos parâmetros do PNAE, com adequação de 105,5\%. Pode-se afirmar que o consumo de frutas e hortaliças atendeu à recomendação do PNAE, assim como a oferta desses alimentos para os alunos de 6 a 15 anos de idade. Esse pano- rama pode ter melhorado ao longo do tempo, com a publicação da resolução de $2013,{ }^{5}$ pois pesquisa realizada, em 2009, nas escolas de Chapecó-SC, mostrou que a oferta de verduras e legumes foi baixa (adequação de $42,8 \%$ ), ocorrendo o mesmo com as frutas (28,6\% de adequação). ${ }^{22}$

As sobras sujas referentes às 20 preparações avaliadas mostram que houve uma grande variedade de alimentos desperdiçados, o que confirma por que alguns nutrientes não atingiram a recomendação nutricional (Tabela 5).

Tabela 5 - Sobras sujas de alunos de 6 a 10 anos e de 11 a 15 anos de idade.

\begin{tabular}{|c|c|c|c|}
\hline \multicolumn{2}{|c|}{ Alunos de 6 a 10 anos de idade } & \multicolumn{2}{|c|}{ Alunos de 11 a 15 anos de idade } \\
\hline Total sobras (gramas) & Peso sobras/aluno & Total sobras (gramas) & Peso sobras/aluno \\
\hline 3072 & 43,89 & 0 & 0 \\
\hline 1080 & 10,29 & 0 & 0 \\
\hline 3543 & 53,68 & 82 & 27,33 \\
\hline 2200 & 19,64 & 0 & 0 \\
\hline 5403 & 56,28 & 672 & 39,53 \\
\hline 314 & 5,61 & 649 & 54,08 \\
\hline 6567 & 78,18 & 707 & 176,75 \\
\hline 2895 & 43,21 & 257 & 257 \\
\hline 1375 & 10,42 & 0 & 0 \\
\hline 4836 & 79,28 & 226 & 28,25 \\
\hline 3451 & 41,58 & 0 & 0 \\
\hline 1039 & 16,23 & 0 & 0 \\
\hline 2947 & 52,62 & 0 & 0 \\
\hline 2873 & 41,64 & 373 & 37,3 \\
\hline 1304 & 11,15 & 15 & 5 \\
\hline 6919 & 103,26 & 653 & 50,23 \\
\hline 3080 & 34,22 & 0 & 0 \\
\hline 1884 & 14,38 & 554 & 32,59 \\
\hline 2006 & 27,86 & 35 & 17,5 \\
\hline 4517 & 69,49 & 489 & 32,6 \\
\hline
\end{tabular}


Scorsin avaliou o desperdício de alimentos em uma escola estadual do município de Guarapuava-PR, em que os índices de sobras se apresentaram superiores aos recomendados pela literatura. ${ }^{23}$

Diante dos valores das sobras referentes a cada aluno por faixa etária, verifica-se a necessidade da padronização das porções e a realização de testes de aceitabilidade na alimentação escolar, a fim de evitar o desperdício melhorando a qualidade da alimentação escolar.

Para a elaboração do cardápio da alimentação escolar devem ser considerados os hábitos alimentares dos alunos, o horário em que as refeições serão servidas, o valor per capita gasto com a alimentação, a faixa etária a ser atendida, a preparação, a aparência do alimento ou a preparação, o sabor, a cor, a aceitação da alimentação, e também devem ser inseridos alimentos que sejam da época naquela região. Pesquisa realizada em duas capitais brasileiras, Florianópolis e Belém, avaliou o planejamento de cardápios para escolas públicas municipais, com base nos parâmetros da Resolução/FNDE n ${ }^{\circ}$. 38, de 2009. Os resultados indicaram que quanto ao planejamento da alimentação, as duas capitais possuíam nutricionistas responsáveis que eram encarregadas pelo mesmo. Quanto ao número de cardápios, em Belém era elaborado um cardápio para todas as unidades de ensino com preparações diferenciadas para alunos da pré-escola, escola parcial ou integral. Em Florianópolis, havia oito modelos de cardápios, os quais eram diferenciados pela modalidade de ensino e período de atendimento, e para cada semana do mês. No que se refere à oferta de frutas e hortaliças, em Belém houve uma oferta con- siderada baixa, inferior a três porções semanais. Já em Florianópolis, a oferta de frutas e legumes ocorria diariamente. No quesito da oferta de alimentos proibidos, conforme a Resolução no. 38, de 2009 do PNAE, foi encontrado no cardápio de Belém o refresco artificial. E, quanto à aquisição de alimentos provindos diretamente da agricultura familiar e/ou do empreendedor familiar rural, não foi efetuada nas duas capitais no ano de 2010. Os argumentos foram que possuíam poucos produtores e que não tinham estrutura suficiente para atender à demanda, assim como careciam de documentos necessários. Em Belém, o fornecimento dos alimentos era realizado por meio de quatro fornecedores e em Florianópolis os fornecedores eram as empresas que ganhavam o edital de compras. ${ }^{6}$

A falta de padronização quanto ao tamanho das porções oferecidas, a quantidade de ingredientes nas preparações ou a falta de alguns deles, e o não seguimento do cardápio, foram os possíveis fatores que podem ter impedido a oferta de alimentos para atender às necessidades nutricionais preconizadas. A presença do nutricionista no âmbito escolar, um bom planejamento dos cardápios ofertados, assim como a realização de treinamentos e recomendações, são importantes para que haja uma distribuição igualitária dos alimentos ofertados pela alimentação, a fim de suprir as necessidades nutricionais dos alunos da rede escolar.

\section{CONSIDERAÇÕES FINAIS}

Os resultados obtidos mostraram que houve maior adequação quanto à oferta da alimentação escolar quando comparado ao 
consumo para os alunos do $1^{\circ}$. ao $5^{\circ}$. ano das escolas parciais da rede municipal de Realeza-PR.

A oferta supriu as recomendações dos macronutrientes para ambas as faixas etárias da pesquisa, porém a oferta dos micronutrientes e fibras teve menor adequação quanto à recomendação preconizada pelo Programa Nacional de Alimentação Escolar.

Nota-se que a faixa etária que possuiu maior adequação quanto às recomendações do PNAE foi a dos alunos de 6 a 10 anos de idade.

A falta de padronização quanto às porções oferecidas é um fator que pode ter influenciado na inadequação da oferta e consumo da alimentação escolar dos alunos de 11 a 15 anos de idade, estes que necessitam de maiores quantidades de nutrientes comparando a outra faixa etária.

A realização da análise sensorial e testes de aceitabilidade com maior frequência podem auxiliar na diminuição dos desperdícios da alimentação escolar.

As frutas e hortaliças foram ofertadas em quantidades adequadas na semana de avaliação desses alimentos, porém ao avaliar a oferta e o consumo dos micronutrientes, estes foram os que tiveram os menores percentuais de adequação.

Os cardápios devem passar por algumas reformulações, visando maior oferta de micronutrientes, principalmente vitamina $\mathrm{A}$, cálcio e as fibras, pois foram os nutrientes que tiveram a menor oferta.

Quanto às limitações desta pesquisa, é possível verificar que o fato da realização do sorteio para avaliar as preparações pode ter influenciado quanto aos resultados.

Faz-se necessário a realização de pesquisas referentes ao desperdício da alimentação escolar, além da adesão e testes de aceitabilidade para verificar a situação em que a alimentação escolar se encontra.

\section{Autoria}

DAS concebeu e delineou o estudo, bem como analisou e interpretou os dados. DAS e CER redigiram o artigo e procederam à revisão crítica e aprovação da versão final.

\section{REFERÊNCIAS}

1. Brasil. Casa Civil/Subchefia para Assuntos Jurídicos. Decreto nº 591, de 6 de julho de 1992. Atos Internacionais. Pacto Internacional sobre Direitos Econômicos, Sociais e Culturais. Promulgação. Publicado no Diário Oficial da União de 7 de julho de 1992.

2. Brasil. Constituição Federal de 1988. Emenda Constitucional no ${ }^{\circ}$ 59, de 11 de novembro de 2009. Acrescenta $₫ 3^{\circ}$. ao artigo 76 do Ato das Disposições Constitucionais Transitórias, dá nova redação aos incisos I e VII do artigo 208, de forma a ampliar a abrangência dos programas suplementares para todas as etapas da educação básica.

3. Peixinho A., Balaban D., Rimkus L., Schwartzman F., Galante AP. Alimentação escolar no Brasil e nos Estados Unidos. Revista O Mundo da Saúde. 2011; 35(2): 128-36.

4. Brasil. Lei no. 11.947, de 16 de junho de 2009. Dispõe sobre o atendimento da alimentação escolar e do Programa Dinheiro Direto na Escola aos alunos da educação básica. Publicada no Diário Oficial da União de 17.6.2009.

5. Brasil. Ministério da Educação. Fundo nacional de Desenvolvimento da Educação/Conselho Deliberativo. Resolução no. 26, de 17 de junho de 2013. Dispõe sobre o atendimento da alimen- 
tação escolar aos alunos da educação básica no âmbito do Programa Nacional de Alimentação Escolar - PNAE. Publicada no Diário Oficial da União de 17 de junho de 2013.

6. Gabriel CG, Costa LCF, Calvo MCM, Vasconcelos FAG. Planejamento de cardápios para escolas públicas municipais: reflexão e ilustração desse processo em duas capitais brasileiras. Rev Nutr. 2012; 25(3): 63-372.

7. Vidal GM, Veiros MB, Sousa AA. School menus in Santa Catarina: evaluation with respect to the National School Food Program regulations. Rev Nutr. 2015; 28(3): 277-87.

8. Gabriel GC, Goulart G., Calvo MCM. Gestão municipal do Programa Nacional de Alimentação Escolar nas capitais da região Sul do Brasil. Rev Nutr. 2015; 28(6): 667-80.

9. Amorim ALB, Rosso VV, Bandoni DH. Acquisition of family farm foods for school meals: analysis of public procurements within rural family farming published by the cities of São Paulo State. Rev Nutr. 2016; 29(2): 297-306.

10. Ferigollo D., Kirsten VR, Heckler D., Figueredo OAT, Perez-Cassarino J., Triches RM. Aquisição de produtos da agricultura familiar para alimentação escolar em municípios do Rio Grande do Sul. Rev Saúde Pública. 2017; 51:6.

11. Silverio GA, Sousa AA. Organic foods from family farms in the National School Food Program: Perspectives of social actors from Santa Catarina, Brazil. Rev Nutr. 2014; 27(3): 289-300.

12. Tabela Brasileira de Composição de Alimentos / NEPA - UNICAMP, 4. ed. rev. e ampl. Campinas: NEPA - UNICAMP, 2011, 161 p. Disponível em: https://www.unicamp.br/nepa/taco/contar/taco_versao2.pdf.

13. Brasil. Ministério da Saúde/Ministério do Planejamento, Orçamento e Gestão. Pesquisa de Orçamentos Familiares 2008-2009: tabela de composição nutricional dos alimentos consumidos no Brasil. Rio de Janeiro, 2011. Disponível em: http://biblioteca.ibge.gov.br/visualizacao/livros/ liv50002.pdf

14. Philippi, ST. Tabela de Composição de Alimentos: suporte para decisão nutricional, 4. ed. Manole, 2013.

15. Matihara $\mathrm{CH}$, Trevisani TS, Garutti S. Valor nutricional da merenda escolar e sua aceitabilidade. Revista Saúde e Pesquisa. 2010; 3: 71-7.

16. Neitzke L., Molina MDCB, Salaroli LB. Adequação nutricional da alimentação escolar em município rural. Espírito Santo, Brasil. Nutrire (Rev Soc Bras Alim Nutr). 2012; 37(1): 1-12.

17. Alves E., Marques AG, Bennemann RM. Avaliação da composição nutricional e da aceitabilidade da merenda oferecida na rede municipal de ensino da cidade de Maringá-PR. Enciclopédia Biosfera Centro Científico Conhecer. 2015; 11(22): 2.015-3.195.

18. Silva MMDC, Gregório EL. Avaliação da composição nutricional dos cardápios da alimentação escolar das escolas da rede municipal de Taquaraçu de Minas-MG. HU Revista. 2012; 37(3): 387-94.

19. Azevedo FG, Magalhães MAM, Ribeiro MS, Silva TF. Avaliação dos cardápios do Programa de Alimentação Escolar em tempo integral do Município de Governador Valadares quanto à adequação nutricional e custo. [Monografia]. Universidade Vale do Rio Doce - UNIVALE. Governador Valadares, 2010.

20. Carvajal AESS, Koehnlein EA, Bennemann RM. Avaliação da merenda de uma Escola Municipal de $1^{\text {a }}$ a $4^{\text {a }}$. série de Maringá-PR. VI EPCC Encontro Internacional de Produção Científica Cesumar. Maringá: Centro Universitário de Maringá, 2009.

21. Borsa MP. Adesão e aceitabilidade da alimentação escolar oferecida nas instituições de ensino fundamental de tempo integral do município de Realeza-PR. Universidade Federal da Fronteira Sul. Trabalho de Conclusão de Curso (Monografia). Realeza, 2014. 
22. Teo CRP, A. et al. Programa nacional de alimentação escolar: adesão, aceitação e condições de distribuição de alimentação na escola. Nutrire (Rev Soc Bras Alim Nutr). 2009; 34(3): 165-85.

23. Scorsin M. Desperdício de alimentos em uma escola estadual do município de Guarapuava-Paraná; Trabalho de Conclusão de Curso (Monografia). Guarapuava, Universidade Estadual do Centro-Oeste - UNICENTRO, 2011.

\section{DAdos DAS AUTORAS}

\section{Camila Elizandra Rossi}

Doutoranda do Programa de Pós-graduação em Nutrição da Universidade Federal de Santa Catarina. Professora Adjunta do curso de graduação em Nutrição da Universidade Federal da Fronteira Sul. Realeza/PR - Brasil. camilarossi@uffs.edu.br

\section{Dainane Aparecida Da Silva}

Graduada em Nutrição pela Universidade Federal da Fronteira Sul. Nutricionista Supervisora Operacional na empresa Risotolândia. Paranaguá/PR. daiasilva32@gmail.com

Submetido em: 26-5-2017

Aceito em: 3-8-2017 